\title{
PATTERNS OF ALCOHOL USE ON A SOUTH AFRICAN UNIVERSITY CAMPUS: THE FINDINGS OF TWO ANNUAL DRINKING SURVEYS
}

\author{
Charles Young \& Vivian de Klerk \\ Rhodes University \\ Grahamstown, South Africa
}

\begin{abstract}
While alcohol continues to be abused on university campuses around the world, the precise situation on South African campuses is unknown. This paper attempts to address this gap by reporting the results of two annual surveys of alcohol consumption amongst students at Rhodes University, the smallest tertiary institution in South Africa, with an annual intake of approximately 6000 students. The results of a survey using the Alcohol Use Disorders Identification Test (AUDIT) suggests that alcohol consumption amongst these students is a public health concern, and likely to result in serious medical and social consequences.
\end{abstract}

KEY WORDS: Alcohol use, binge drinking, South Africa, university students, AUDIT

\section{INTRODUCTION}

It is probably uncontroversial to state that most university campuses struggle with containing and controlling alcohol consumption by their students, since the age at which students first enter such institutions is an age of freedom and experimentation, where young people have the opportunity to test the limits previously set by parents and schools. At Rhodes University, there has been a long history of efforts to control excessive alcohol use.

Rhodes is primarily a residential university, and it occupies a very prominent position in the small town of Grahamstown. Firstly, it is the primary employer and is very visible, situated as it is near the centre of town, and occupying a relatively large area; secondly, the annual influx of students has a very significant impact on the town in terms of sheer numbers, and the fact that approximately 3000 of them rent accommodation or "digs" from local inhabitants; thirdly, the students bring with them significant spending power for the nine months per year that they live in Grahamstown, and local shops and bars are very keen to make the best of this opportunity.

While the level of drinking at Rhodes University is possibly no higher than that at any other university in South Africa, it does have a rather undesirable reputation as the "drinking university", and the reason for this is twofold: firstly, the drinking behaviour is highly visible, because of the size of the town, and because of the location of many off-campus pubs and bars near to the university. This means that Rhodes students pursue their after- 
hours relaxation in a very concentrated, small area, whereas in a large city, university students are doing the same thing, but anonymously. Secondly, because of the small size of the university as a whole, students at Rhodes have very strong social networks, and many enjoy this aspect of their university experience.

That said, Rhodes University nonetheless regards the problem of drinking as a serious one, which deserves urgent attention. It has long been the topic of debate, and the survey which is the topic of this paper was one strategy aimed at changing this 'drinking culture'.

\section{The consequences of excessive alcohol consumption on university campuses}

Research from around the world, particularly in the US and UK, suggests that university drinking is characterised by excess (Karam, Kypri, \& Salamoun, 2007). A UK survey involving ten universities, for example, reported that $61 \%$ of male students and $48 \%$ of female students exceed the safe drinking limits (Webb, Ashton, Kelly \& Kamali, 1996). In the US, national surveys repeated four times between 1993 and 2001 reveal that more than $40 \%$ of college students binge drink (Wechsler \& Nelson, 2008).

This level of alcohol misuse is associated with a range of a range of social, health and educational problems, and students are at particular risk of these alcohol-related harms (Wechsler, Davenpoort, Moeykens, \& Castillo, 1994). In the US, binge drinking is reported to be the leading cause of death and injury among college students (Hingson, Heeren, Zakocs, Kopstein, \& Wechsler, 2002). Alcohol misuse is also associated with unsafe sex (Wechsler, Lee, Kuo, Lee, 2000); absenteeism and academic failure (Powell, Williams, Wechsler, 2004; Wechsler, Lee, Kuo, et al., 2002); and antisocial behaviour and criminal justice problems (Wechsler, Lee, Kuo,et al., 2002).

Moreover, the deleterious effects of student drinking are not confined to those who drink: students living amongst high proportions of binge drinkers experience more incidences of verbal, physical and sexual assault, and frequently have their sleep and studies disturbed (Wechsler, Moeykens, Davenport, Castillo, \& Hansen, 1995); while the neighbourhoods in the vicinity of university campuses where student drinking is problematic are affected by the noise and vandalism (Wechsler, Lee, Hall, Wagenaar, Lee, 2002).

Other studies have suggested that university and college students report a higher prevalence of alcohol disorders and harm than those young people not at college or university (Dawson, Grant, Stinson, \& Chou, 2004; Kyrpi, Cronin, \& Wright, 2005). It is clear that some aspect of the university or college experience predisposes students to overuse alcohol and makes them vulnerable to alcohol use disorders (though perhaps not necessarily for alcohol dependence (Slutske, 2005)).

It is evident that the drinking culture of an institution has a strong impact on the drinking behaviour of new students, where people in environments that sanction heavy drinking are much more likely to drink excessively themselves (Skog, 1980, 1985). Research in the US indicates that while the drinking behaviour varies greatly amongst different colleges, it remains fairly consistent within colleges (Wechsler, Lee, Kuo, et al., 2002), suggesting that the drinking cultures are not easily changed. In South Africa, the media and advertising undoubtedly promote the idea 
that drinking is 'cool'. Combined with the sudden freedom from prohibitions on drinking which supposedly prevail at schools and at home, many first-year students are vulnerable to the strong peer pressure that is encountered at University. The sudden shift in influence from parents and guardians to peers, and the urgent need to make new friends, establish peer networks and develop an identity in this new social environment often involves alcohol (Martin \& Hoffman, 1993). Borsari and Carey (2001) argue that this peer influence involves at least three different processes: direct peer influence, modelling and social norms.

According to these researchers, students exert different kinds of social pressure on those peers who drink less than they do, ranging from subtle and indirect remarks to more aggressive and confrontational approaches to encourage them to drink more. Research also indicates that students who are exposed to the example of more senior students who drink excessively are more likely themselves to drink heavily. Finally, the literature suggests that students are likely to overestimate the alcohol consumption of others, and that these perceived norms act as a significant influence on personal alcohol use. Since excessive alcohol consumption appears, to first-time entering students, to be common and acceptable, they are more likely to adopt similar practices.

So while much research suggests that alcohol is abused with serious consequences at many universities around the world (Karam et al., 2007), and media reports suggest that the situation in South Africa is not different (see, for example, Govender, 2007), the actual prevalence of alcohol misuse on South African campuses is not accurately known. What is evident is that as a country undergoing rapid socioeconomic change, South Africa has seen an increase in substancerelated problems (Pluddermann et al., 2004), and of all the substances abused in South Africa, alcohol dominates (Parry et al., 2002). Given that drinking is a national problem, the situation amongst South African students is also likely to be a public health concern, particularly so in a country where the rampant crime, the high prevalence of HIV infection and poor educational resources exacerbate the harmful effects of alcohol misuse. It is clear that more accurate data are required before the prevalence of this abuse can be properly assessed, so that appropriate and effective public health interventions can follow.

\section{Features of university / college environments associated with excessive drinking}

A number of variables have been identified that are implicated in excessive drinking on campuses. The combination of these results in what Wechsler and Nelson (2008), and others, refer to as 'wet environments'.

Firstly, binge drinking is inversely correlated to the amount of supervision in the living environments (Harford, Wechsler \& Muthen, 2002; Wechsler, Lee, Nelson, \& Kuo, 2002). At Rhodes University approximately half the students live in university residences, while most of the others rent private accommodation in town. These private rentals are mostly unsupervised, while residence management attempt to limit drinking in the university halls. All are within fairly close proximity to a number of drinking outlets on campus and in town.

Another factor implicated in the levels of student drinking is to do with the demographic profile of the student body. 
Lower drinking rates are associated with ethnically diverse student bodies (Wechsler \& Kuo, 2003). The same is true of student demographics that include a high proportion of female and senior students. A comparison, therefore, of alcohol use amongst students according to gender, race and year of study is necessary to be able to better describe the distribution of drinking behaviour at Rhodes University.

Incidentally, there is debate in the social science literature about the appropriateness of using racial categories in survey research (see Bowman, Seedat, Duncan \& Burrows (2006) for an outline of this debate). The consensus seems to be that while these are socially constructed terms, they continue to shape social relations in South Africa. The variable race was not collected in 2007 when the survey was first administered, but because race is a cultural reality for most South Africans and because attendance at many of the pubs and bars in Grahamstown appears to be along racial lines, this was rectified in 2008.

\section{Categories of Alcohol Misuse}

The World Health organisation defines different categories of alcohol consumption along the continuum of safe to dangerous drinking as 'hazardous', 'harmful' and 'dependent' (Babor, Campbell, Room, \& Saunders, 1994).

Hazardous drinking is a pattern of alcohol use that increases the risk of harmful consequences for the drinker without having yet caused any alcoholrelated harm. This category applies to men and women who exceed the Royal Colleges' (1995) recommended limits of 21 and 14 units of alcohol each week respectively $(1$ unit $=10 \mathrm{mg}$ of pure alcohol; a standard glass of wine $=2$ units and $\mathrm{a}$ beer $=2$ units).
Binge drinking, or heavy episodic drinking, is included in the hazardous category, even if the weekly limits are not exceeded, because it generally involves rapid and excessive drinking over a relatively short period of time, which intensifies the effects. Although a range of definitions exist (Gill, 2002; McAlaney $\&$ McMahon, 2007), a thorough review of alcohol treatments defines bingeing as drinking eight or more units in one session for men and six or more units for women (Raistrick, Heather, \& Godfrey, 2006).

Harmful drinking is defined by the ICD-10 Classification of Mental and Behavioural Disorders (WHO, 1992) as a pattern of drinking that is already causing physical or mental health damage to the drinker, but without meeting the full clinical criteria of alcohol dependence.

Dependent drinking is a pattern of drinking characterised by moderate or severe dependence on alcohol. The ICD10 (WHO, 1992) defines alcohol dependence as a cluster of symptoms that include a strong desire to use alcohol, impaired control over alcohol use, physiological withdrawal when alcohol consumption is reduced, greater tolerance of alcohol, neglect of alternative pleasures and interests, and persistence with drinking, despite clear evidence of harmful consequences.

\section{METHOD}

\section{Participants}

2049 students (1198 female and 851 males students, mean age $=21$ years and 3 months) completed the survey in 2007, representing slightly more than one third of all registered students, while 1119 (644 female and 475 male students, mean age $=21$ years and 1 month) completed the survey in 2008. 
PATTERNS OF ALCOHOL USE ON A SOUTH AFRICAN UNIVERSITY CAMPUS:

\section{THE FINDINGS OF TWO ANNUAL DRINKING SURVEYS}

\section{The Measure}

The Alcohol Use Disorders Identification Test (AUDIT) is a reliable and valid measure developed by the World Health Organisation (WHO) (Allen, Litten, Fertig, \& Babor, 1997; Saunders, Aasland, Babor, De La Fuente, \& Grant, 1993). AUDIT is reported to have a sensitivity of $92 \%$ and specificity of $94 \%$ in detecting hazardous or harmful alcohol use (Saunders et al., 1993). Moreover, the test has been translated into numerous languages, appears to be crossculturally valid, is quick to complete and easily scored, and, as a result, is widely used in research and practical settings (Allen et al., 1997; Babor, Higgins-Biddle, Saunders, \& Monteiro, 2001).

A further advantage is that AUDIT has been used in several studies involving university settings (see, for example, Andersson, Johnsson, Berglund, \& Ojehagen, 2007; Fleming, Barry, \& MacDonald, 1991; Granville-Chapman, Yu, \& White, 2001; Kypri, Langley, McGee, Saunders, \& Williams, 2002; McShane \& Cunningham, 2003; O'Hare \& Sherrer, 1999; Shields, Guttmannova, $\&$ Caruso, 2004). For this reason it was selected as a suitable measure to ascertain levels of usage in this survey.

The measure consists of ten items: three on alcohol consumption, four on alcohol related problems and adverse reactions, and three on dependence symptoms. Each item has a score ranging from 0 to 4 and the maximum score is 40 ; the higher the total score, the more dangerous the drinking. AUDIT is a useful predictor of alcohol-related social and medical problems (Conigrave \& Saunders, 1995), with a score of eight or more being associated with future problems. In general, a score of 8 to 15 is regarded as hazardous drinking, 16 to 19 as harmful drinking, and 20 or more as alcohol dependence.

\section{Procedure}

The purpose of this study was to determine the prevalence and distribution of safe, hazardous, harmful and dependent drinking amongst students of Rhodes University. A number of important variables are considered, including sex, race, year of study and living arrangements. An ad hoc sample survey was used to obtain these data. The AUDIT Test was incorporated into the Rhodes University StudentZone website in such a way that all registered students would have the opportunity to complete the test only once. The University and students are increasingly using the internet to post announcements and other information, and this was deemed to be the most effective way of reaching the entire student population.

The data were collected over two weeks in October 2007 and 2008. The test took only a few minutes to complete, and all students who submitted responses were assured of anonymity.

\section{Statistical Analysis}

ANOVA and chi-square are used to describe differences between populations. Since the data are subjected to a number of statistical analyses, alpha is set at 0.01 rather than the usual 0.05 to reduce the family-wise error rate.

\section{RESULTS}

Table 1 presents this data according to the different categories of drinking.

\section{Total Scores}

The average AUDIT scores for the total sample in 2007 and 2008 are 8.94 and 8.84 respectively. The difference is 
small and not statistically significant $(\mathrm{t}=$ $0.38, \mathrm{df}=3166, \mathrm{p}=0.70$ ).
Table 2 presents the overall descriptive statistics.

Table 1. Categories of Drinking for 2007 and 2008

\begin{tabular}{|c|c|c|c|c|c|c|c|c|}
\hline Characteristics & Safe & & \multicolumn{2}{|c|}{ Hazardous } & \multicolumn{2}{|c|}{ Harmful } & \multicolumn{2}{|c|}{ Dependent } \\
\hline 2007 & 2007 & & & & & & & \\
\hline Female & 689 & $57.5 \%$ & 352 & $29.4 \%$ & 75 & $6.3 \%$ & 82 & $6.8 \%$ \\
\hline Male & 311 & $36.5 \%$ & 320 & $37.6 \%$ & 100 & $11.8 \%$ & 120 & $14.1 \%$ \\
\hline Total & 1000 & $48.8 \%$ & 672 & $32.8 \%$ & 175 & $8.5 \%$ & 202 & $9.9 \%$ \\
\hline 2008 & 2008 & & & & & & & \\
\hline Female & 374 & $58.1 \%$ & 192 & $29.8 \%$ & 40 & $6.2 \%$ & 38 & $5.9 \%$ \\
\hline Male & 183 & $38.5 \%$ & 182 & $38.3 \%$ & 47 & $9.9 \%$ & 63 & $13.3 \%$ \\
\hline Total & $\begin{array}{l}557 \\
2008\end{array}$ & $49.8 \%$ & 374 & $33.4 \%$ & 87 & $7.8 \%$ & 101 & $9.0 \%$ \\
\hline White & 290 & $43.2 \%$ & 244 & $36.3 \%$ & 65 & $9.7 \%$ & 73 & $10.9 \%$ \\
\hline Black & 214 & $58.3 \%$ & 106 & $28.9 \%$ & 21 & $5.7 \%$ & 26 & $7.1 \%$ \\
\hline Coloured & 16 & $57.1 \%$ & 10 & $35.7 \%$ & 0 & $0.0 \%$ & 2 & $7.1 \%$ \\
\hline Indian & $\begin{array}{l}37 \\
2007\end{array}$ & $71.2 \%$ & 14 & $26.9 \%$ & 1 & $1.9 \%$ & 0 & $0.0 \%$ \\
\hline Undergraduate & 859 & $49.1 \%$ & 562 & $32.1 \%$ & 148 & $8.5 \%$ & 182 & $10.4 \%$ \\
\hline Postgraduate & $\begin{array}{l}141 \\
2008\end{array}$ & $47.3 \%$ & 110 & $36.9 \%$ & 27 & $9.1 \%$ & 20 & $6.7 \%$ \\
\hline Undergraduate & 464 & $47.9 \%$ & 332 & $34.3 \%$ & 79 & $8.2 \%$ & 93 & $9.6 \%$ \\
\hline Postgraduate & $\begin{array}{l}93 \\
2007\end{array}$ & $61.6 \%$ & 42 & $27.8 \%$ & 8 & $5.3 \%$ & 8 & $5.3 \%$ \\
\hline Res & 622 & $49.8 \%$ & 418 & $33.4 \%$ & 98 & $7.8 \%$ & 112 & $9.0 \%$ \\
\hline Digs & 350 & $46.7 \%$ & 242 & $32.3 \%$ & 74 & $9.9 \%$ & 84 & $11.2 \%$ \\
\hline Parental & $\begin{array}{l}28 \\
2008\end{array}$ & $57.1 \%$ & 12 & $24.5 \%$ & 3 & $6.1 \%$ & 6 & $12.2 \%$ \\
\hline Residence & 365 & $49.8 \%$ & 253 & $34.5 \%$ & 58 & $7.9 \%$ & 57 & $7.8 \%$ \\
\hline Digs & 175 & $48.9 \%$ & 114 & $31.8 \%$ & 29 & $8.1 \%$ & 40 & $11.2 \%$ \\
\hline Parental home & 17 & $60.7 \%$ & 7 & $25.0 \%$ & 0 & $0.0 \%$ & 4 & $14.3 \%$ \\
\hline
\end{tabular}

Table 2. Overall Descriptive Statistics for the AUDIT Survey

\begin{tabular}{lrllllllll}
\hline Characteristics & $\begin{array}{l}2007 \\
\text { Total }\end{array}$ & $\%$ & $\begin{array}{l}\text { Average } \\
\text { AUDIT } \\
\text { Score }\end{array}$ & SD & $\begin{array}{l}\text { Tota } \\
1\end{array}$ & $\%$ & $\begin{array}{l}\text { Average } \\
\text { AUDIT } \\
\text { Score }\end{array}$ & SD \\
\hline Gender & 851 & 41.5 & 10.9 & 7.67 & 475 & 42.4 & 10.56 & 7.24 \\
$\quad$ Male & 1198 & 58.5 & 7.56 & 6.48 & 644 & 57.6 & 7.58 & 6.35 \\
$\quad \begin{array}{l}\text { Female } \\
\text { Total }\end{array}$ & 2049 & 100 & 8.94 & 7.2 & 1119 & 100 & 8.84 & 6.90 \\
$\begin{array}{l}\text { Level of } \\
\text { education }\end{array}$ & & & & & & & &
\end{tabular}


PATTERNS OF ALCOHOL USE ON A SOUTH AFRICAN UNIVERSITY CAMPUS: THE FINDINGS OF TWO ANNUAL DRINKING SURVEYS

\begin{tabular}{lrrrrrrrr} 
Undergraduate & 1751 & 85.5 & 8.97 & 7.32 & 968 & 86.5 & 9.05 & 7.02 \\
Postgraduate & 298 & 14.5 & 8.79 & 6.38 & 151 & 13.5 & 7.56 & 5.92 \\
Year of study & & & & & & & & \\
1st & 627 & 30.6 & 8.49 & 7.16 & 425 & 38.0 & 8.87 & 7.02 \\
2nd & 568 & 27.7 & 9.13 & 7.33 & 284 & 25.4 & 8.94 & 6.72 \\
3rd & 486 & 23.7 & 9.13 & 7.36 & 215 & 19.2 & 9.09 & 7.14 \\
4th & 257 & 12.5 & 9.35 & 7.19 & 135 & 12.1 & 8.41 & 6.78 \\
5th & 111 & 5.4 & 8.77 & 5.73 & 60 & 5.4 & 8.27 & 6.43 \\
Accommodation & & & & & & & & \\
Residence & 1250 & 61.0 & 8.59 & 7.13 & 733 & 65.5 & 8.56 & 6.69 \\
Digs & 750 & 36.6 & 9.55 & 7.23 & 358 & 32.0 & 9.47 & 7.28 \\
Parental home & 49 & 2.4 & 8.57 & 7.57 & 28 & 2.5 & 8.21 & 7.17 \\
Race & & & & & & & & \\
White & - & - & - & - & 672 & 60.1 & 10.02 & 6.63 \\
Indian & - & - & - & - & 52 & 4.6 & 5.19 & 4.84 \\
Coloured & - & - & - & - & 28 & 2.5 & 5.98 & 5.98 \\
Black & - & - & - & - & 367 & 32.8 & 7.31 & 7.22 \\
\hline
\end{tabular}

The distribution in 2007 for the total scores is very similar to that obtained in 2008 with no statistically significant differences $\left(\square^{\square}=1.43\right.$, df $=3, \mathrm{p}=$ $0.490)$. Both sets of results suggest that half of the students who completed the questionnaire exceed the clinical cut-off score of eight and therefore risk alcoholrelated harm. About one third of all students who completed the questionnaire fall into the hazardous drinking category, while the remainder are drinking harmfully or are dependent on alcohol.

\section{Gender}

The AUDIT scores for men are statistically significantly higher than they are for women for both years $\left(F_{(1}\right.$, $3164)=147.673, \mathrm{p}=0.000)$. There was no significant interaction between sex and year $\left(F_{(1,3164)}=0.447, \mathrm{p}=0.504\right)$. Also, the proportions in the different categories of drinking differ according to sex for both years, with men being more likely to be located in the hazardous, harmful and dependent categories (2007: $\square^{2}=99.2$, df $=3, \mathrm{p}=0.000 ; 2008: \square^{2}=48.1, \mathrm{df}=3, \mathrm{p}$ $=0.000)$.

\section{Race}

The variable race was included in the survey questionnaire in 2008 only. The data reveal that white students drink more than any of the other groups on campus, a difference that is statistically significant $\left(F_{(3,1115)}=18.594, \mathrm{p}=0.000\right)$. Moreover, white students are more likely than black, Indian and coloured students to occupy the hazardous, harmful and dependent drinking categories $\left(\square^{2}=33.1\right.$, df $=3, \mathrm{p}=$ 0.000).

To get an indication of whether this might be related to academic performance, the 2007 pass rates for male and female students were obtained from the Rhodes University Data Processing Unit and are described in Table 3 below. The Table reveals that a greater proportion of female than male students pass all their subjects in each year of study (a phenomenon that is repeated yearly since 2004). The differences between the total number of female and male students who pass all their subjects compared to those who do not pass all their subjects is statistically significant $\left(\square^{2}=26.4\right.$, df $\left.=1, \mathrm{p}=0.000\right)$. 
Table 3. Proportions of Students who passed all Subjects by Gender in 2007

\begin{tabular}{lcccccccc}
\hline Gender & $\mathrm{n}$ & $\begin{array}{c}\text { 1st Year } \\
\%\end{array}$ & $\mathrm{n}$ & $\begin{array}{c}\text { 2nd Year } \\
\%\end{array}$ & $\mathrm{n}$ & $\begin{array}{c}\text { 3rd Year } \\
\%\end{array}$ & $\mathrm{n}$ & $\begin{array}{c}\text { 4th Year } \\
\%\end{array}$ \\
\hline Male & 233 & 45.4 & 203 & 46.4 & 286 & 67.9 & 12 & 54.6 \\
Female & 386 & 55.9 & 328 & 56.5 & 392 & 73.3 & 34 & 79.1 \\
\hline
\end{tabular}

Undergraduate and postgraduate students

Though there is a greater difference in mean AUDIT scores between undergraduates and postgraduates in 2008 compared to 2009 , the differences are not statistically significant $\left(F_{(1,3164)}=\right.$ $4.784, p=0.029)$. A comparison of the proportions in each of the four drinking categories for undergraduate and postgraduate students suggests that neither difference is statistically significant (2007: $\square^{2}=5.57, \mathrm{df}=3, \mathrm{p}=$ $0.134 ; 2008: \square^{2}=10.6$, df $=3, p=$ $0.014)$.

Also, the differences according to the year of study, are not statistically significant $\left(F_{(4,3158)}=0.551, \mathrm{p}=0.698\right)$; nor was there a significant interaction between year of study and the year of data collection $\left(F_{(4,3158)}=0.628, \mathrm{p}=0.642\right)$.

Accommodation

The mean AUDIT scores differ according to accommodation, with students living in private, rented accommodation, referred to as digs, reporting higher scores than those living in residence or in the family home. These differences are statistically significant $\left(F_{(2,3162)}=57.282, \mathrm{p}=0.003\right)$.

However, if we collapse the three groups into two groups of supervised (parental home and residence) and unsupervised (digs), the relationship between level of supervision and drinking category is not statistically significantly related for either year (2007: $\square^{2}=5.80, \mathrm{df}$ $=3, \mathrm{p}=0.122 ; 2008: \square^{2}=3.24, \mathrm{df}=3, \mathrm{p}$ $=0.356$ ).

\section{DISCUSSION}

It is of great concern that half of the respondents to this survey report drinking patterns that are either hazardous, harmful or alcohol dependent and that this drinking culture remains stable across at least the 12 months between collecting the two samples. Apart from the inevitable deleterious effects on health, social functioning and safety, such heavy drinking is also associated with absenteeism and poor academic performance. Thus, it is always in the best interests of institutions of higher learning to take note of the levels of alcohol consumption amongst their students, and devise strategies to counteract excessive drinking.

The matter is of particular concern because the already high prevalence of excessive drinking at a university is likely to influence the drinking behaviour of new students when they first arrive (Borsari \& Carey, 2001; Skog, 1980, 1985). First-time entering students who observe the excessive drinking of others in the social group are more likely to drink excessively themselves. In order to prevent universities from being places where people develop alcohol disorders, university administrations are under considerable pressure, if not obligation, to curtail excessive student drinking where this is possible. However, the data obtained in this study, like in other studies, suggests the university drinking cultures are resilient. 
Male students, in particular, appear to be at risk of alcohol abuse, although one needs to be cautious about interpreting this to mean that women are drinking safely, as there is research evidence to suggest that after an equivalent dose of alcohol, women have higher blood ethanol levels than men do. This is not only because men are usually larger than women, but also because the body composition of women per kilogram of body weight contains less water than men and because decreased gastric alcohol dehydrogenase activity in women means that a greater proportion of the alcohol passes into the bloodstream (Frezza et al., 1990; Lieber, 1997).

The AUDIT measure, though, is not simply a measure of how much a person drinks, but also a measure of the consequences of drinking. Female students, therefore, appear not to be experiencing the same degree of alcoholrelated harm as male students.

It is noteworthy that male students are less likely to pass all their subjects than female students, suggesting that men are being outperformed by women. However, although the connection between excessive consumption and poor academic performance is very plausible and supported by some research, if for no other reason than because heavy drinkers are more likely to miss lectures, one cannot assume that the discrepancy in academic performance between male and female students is caused by the differences in drinking behaviour. It may be that students who perform poorly are more likely to turn to alcohol. It is also likely that there are gender differences in the subject and degree choices that may have some bearing on academic performance. The intersection between gender, alcohol consumption and academic performance is certainly an issue that warrants further investigation.
Furthermore, there is a large and statistically significant difference between the mean AUDIT scores of black and white students. White students are more likely to occupy the hazardous, harmful and dependent categories than black students. Given the economic disparities that persist in South Africa, this may have something to do with the spending power of the relatively wealthy white students. Combined with the observation that the choice of drinking venue differs largely along racial lines, this finding suggests that the problematic drinking culture on campus involves white male students.

This dangerous drinking does not appear to decrease as students progress from one year of study to the next, or even as they progress from undergraduate to postgraduate studies. The drinking culture that students encounter as they enter university appears to persist throughout their university studies. A more precise tracking of the drinking behaviour of a sample of students from the start to the end of their studies would, however, be useful.

Finally, while students living in digs report higher AUDIT scores than those living in the university residences or who live in their family homes, the difference is small. There are restrictions on where and when students can consume alcohol in residence but these are difficult to enforce and obviously residence students are free to drink with little restriction in the various drinking outlets in town.

Given these findings, the university management will continue to intervene to counter the drinking culture that exists at Rhodes University. A number of measures are already in place, including annual alcohol awareness campaigns; a new Responsible Drinking Policy; the training of residence management and student governance to combat excessive drinking in the residences; changes to the 
student discipline procedures to ensure that alcohol-related offences are appropriately punished; the public dissemination and discussion of the results of this survey; the involvement of the off-campus publicans in discussions to contain drinking on and around campus; a get-home-safe project; and numerous alcohol-free social and sporting events to break the association between drinking and pleasure. The publication of this paper will hopefully prepare the way for a coordinated effort amongst South African universities to share data and strategies to contain alcohol abuse on our campuses.

\section{REFERENCES}

Allen, J. P., Litten, R. Z., Fertig, J. B., \& Babor, T. (1997). A review of research on the Alcohol Use Disorders Identification Test (AUDIT). Alcoholism, Clinical and Experimental Research, 21, 613-619.

Andersson, C., Johnsson, K. O., Berglund, M., \& Ojehagen, A. (2007). Alcohol involvement in Swedish university freshmen related to gender, age, serious relationship and family history of alcohol problems. Alcohol and Alcoholism, 42, 448-455.

Babor, T., Campbell, R., Room, R., \& Saunders, J. B. (1994). Lexicon of Alcohol and Drug Terms. Geneva: World Health Organisation.

Babor, T., Higgins-Biddle, J. C., Saunders, J. B., \& Monteiro, M. G. (2001). AUDIT The Alcohol Use Disorders Identification Test: Guidelines for Use in Primary Health Care (2nd ed.). Geneva: World Health Organisation.

Borsari, B., \& Carey, K. (2001). Peer influences on college drinking: A review of the research. Journal of Substance Abuse, 13, 391-424.

Bowman, B., Seedat, M., Duncan, N., \& Burrows, S. (2006). Race, social transformation and redress in the South African social and health sciences. In G. Stevens, V. Franchi \& T. Swart (Eds.), A race against time: Psychology and challenges to deracialisation in South Africa (pp. 91-103). Pretoria: Unisa Press.

Conigrave, K. M., \& Saunders, J. B. (1995). Predictive capacity of the AUDIT questionnaire for alcohol-related harm. Addiction, 90, 1479-1485.

Dawson, D. A., Grant, B. F., Stinson, F. S., \& Chou, P. S. (2004). Another look at heavy episodic drinking and alcohol use disorders among college and noncollege youth. Journal of Studies on Alcohol, 65, 477-489.

Fleming, M. F., Barry, K. L., \& MacDonald, R. (1991). The alcohol use disorders identification test (AUDIT) in a college sample. International Journal of Addictions, 26, 1173-1185.

Frezza, M., DiPadova, C., Pozzato, G., Terpin, M., Baraona, E., \& Lieber, C. S. (1990). High blood alcohol levels in women: The role of decreased gastric alcohol dehydrogenase activity and firstpass metabolism. New England Journal of Medicine, 322, 95-99.

Gill, J. S. (2002). Reported levels of alcohol consumption and binge drinking within the UK undergraduate student population over the last 25 years. Alcohol and Alcoholism, 37, 109-120.

Govender, P. (2007, September, 2). SA students hit the bottle at the expense of books. The Sunday Times.

Granville-Chapman, J. E., Yu, K., \& White, P. D. (2001). A follow-up survey of alcohol consumption and knowledge in medical students. Alcohol and Alcoholism, 36, 540-543.

Harford, T.C., Wechsler, H., \& Muthen, B.O. (2002). The impact of current residence and high school drinking on alcohol problems among college students. Journal of Studies on Alcohol, 63, 271-279.

Hingson, R. W., Heeren, T., Zakocs, R. C., Kopstein, A., \& Wechsler, H. (2002). Magnitude of alcohol-related mortality and morbidity among U.S. college students ages 18-24. Journal of Studies on Alcohol, 63, 136-144.

Karam, E., Kypri, K., \& Salamoun, M. (2007). Alcohol use among college 


\section{THE FINDINGS OF TWO ANNUAL DRINKING SURVEYS}

students: An international perspective. Current Opinion in Psychiatry, 20, 213221.

Kypri, K., Langley, J. D., McGee, R., Saunders, J. B., \& Williams, S. (2002). High prevalence, persistent hazardous drinking among New Zealand tertiary students. Alcohol and Alcoholism, 37, 457-464.

Kyrpi, K., Cronin, M., \& Wright, C. S. (2005). Do university students drink more hazardously than their nonstudent peers? Addiction, 100, 713-714.

Lieber, C. S. (1997). Gender differences in alcohol metabolism and susceptibility. In R. W. Wilsnack \& S. C. Wilsnack (Eds.), Gender and alcohol: Individual and social perspectives (pp. 77-89). Piscataway, NJ: Rutgers Center for Alcohol Studies.

Martin, C. M., \& Hoffman, M. A. (1993). Alcohol expectancies, living environment, peer influence, and gender: A model of college student drinking. Journal of College Student Development, 34, 206-211.

McAlaney, J., \& McMahon, J. (2007). Diagnosing and dealing with the 'new British disease'. The Psychologist, 20, 738-741.

McShane, K. E., \& Cunningham, J. A. (2003). The role of relevancy in normative feedback for university students drinking patterns. Addictive Behaviours, 28, 1523 1528

O'Hare, T., \& Sherrer, M. V. (1999). Validating the alcohol use disorders identification test with college firstoffenders. Journal of Substance Abuse Treatment, 17, 113-119.

Parry, C. D. H., Bhana, A., Myers, B., Pluddermann, A., Siegfried, N., Morojele, N., Flisher, A. J., \& Kozel, N. J. (2002). The South African Community Epidemiology Network on Drug Use (SACENDU): Description, findings (1997-1999) and policy implications. Addiction, 97, 969-976.

Pluddermann, A., Parry, C., Bhana, A., Harker, N., Potgieter, H., Gerber, W., \& Johnson, C. (2004). The South African community epidemiology network on drug use (SACANDU). Research Brief, Phase 16, 7(2).
Powell, L.M., Williams, J., \& Wechsler, H. (2004). Study habits and the level of alcohol use among college students. Education Economics, 12, 135-149.

Raistrick, D., Heather, N., \& Godfrey, C. (2006). Review of the effectiveness of treatment for alcohol problems. London: National Treatment Agency for Substance Misuse.

Royal Colleges. (1995). Alcohol and the Heart in Perspective: Sensible Drinking Reaffirmed, Report of a Joint Working Group of the Royal College of Physicians, the Royal College of Psychiatrists and the Royal College of General Practitioners. London: Royal College of Physicians.

Saunders, J. B., Aasland, O. G., Babor, T. F., De La Fuente, J. R., \& Grant, M. (1993). Development of the Alcohol Use Disorders Identification Test (AUDIT): WHO collaborative project on early detection of persons with harmful alcohol consumption - II. Addiction, 88, 791-804.

Shields, A. L., Guttmannova, K., \& Caruso, J. C. (2004). An examination of the factor structure of the alcohol use disorders identification test in two high-risk samples. Substance use and Misuse, 39, 1161-1182.

Skog, O.-J. (1980). Social interaction and the distribution of alcohol consumption. Journal of Drug Issues, 10, 71-92.

Skog, O.-J. (1985). The collectivity of drinking cultures: a theory of the distribution of alcohol consumption. British Journal of Addiction, 80, 83-99.

Slutske, W. S. (2005). Alcohol use disorders among US college students and their noncollege-attending peers. Archives of General Psychiatry, 62, 321-327.

Webb, E., Ashton, C.H., Kelly, P., \& Kamali, F. (1996). Alcohol and drug use in UK university students. The Lancet, 348, 922-925.

Wechsler, H., Davenpoort, G., Moeykens, B., \& Castillo, S. (1994). Health and behavioural consequences of binge drinking in college. A national survey of students at 140 campuses. Journal of the American Medical Association, 272. 
Wechsler, H., \& Kuo, M. (2003). Watering down the drinks: The moderating effect of college demographics on alcohol use of high-risk groups. American Journal of Public Health, 93, 1929-1933.

Wechsler, H., Lee, J.E., Kuo, M., \& Lee, H. (2000). College binge drinking in the 1990s: A continuing problem: Results of the Harvard School of Public Health 1999 College Alcohol Study. Journal of American College Health, 48, 199-210.

Wechsler, H., Lee, J.E., Hall, J., Wagenaar, A.C., \& Lee, H. (2002). Secondhand effects of student alcohol use reported by neighbors of colleges: The role of alcohol outlets. Social Science \& Medicine, 55, 425-435.

Wechsler, H., Lee, J.E., Kuo, M., Seibring, M., Nelson, T.F., \& Lee, H. (2002). Trends in college binge drinking during a period of increased prevention efforts: Findings from 4 Harvard School of Public Health College Alcohol Study surveys: 1993-2001. Journal of American College Health, 50, 203-217.

Wechsler, H., Lee, J.E., Nelson, T.F., \& Kuo, M. (2002). Underage college students' drinking behavior, access to alcohol, and the influence of deterrence policies: Findings from the Harvard School of
Public Health College Alcohol Study. Journal of American College Health, 50, 223-236.

Wechsler, H., Moeykens, B., Davenport, A., Castillo, S., \& Hansen, J. (1995). The adverse impact of heavy episode drinkers on other college students. Journal of Studies on Alcohol, 56, 628-634.

Wechsler, H., \& Nelson, T.F. (2008). What we have learned from the Harvard School of Public Health College Alcohol Study: Focussing attention on college student alcohol consumption and the environmental conditions that promote it. Journal of Studies on Alcohol and Drugs, 69, 481-490.

WHO. (1992). The ICD-10 Classification of Mental and Behavioural Disorders. Geneva: World Health Organisation.

\section{ACKNOWLEDGEMENTS}

The authors would like to acknowledge the assistance of Mr Michael Morley, of the Information Technology Unit, in placing the survey on the University StudentZone, and of Ms Natalie Ripley in extracting data on student success rates at Rhodes. 